\title{
Hipnose, Dor Crônica e Técnicas de Ancoragem: A Terapia de Dentro para Fora ${ }^{1}$
}

\author{
Maurício da Silva Neubern² \\ Universidade de Brasília
}

\begin{abstract}
RESUMO - O presente trabalho busca resgatar a técnica hipnótica de ancoragem, destacando a condição do sujeito como participante ativo no processo terapêutico. Partindo de algumas ilustrações clínicas com pacientes portadores de dores crônicas, ressalta duas dimensões de grande relevância dessa técnica. Primeiramente, a diagnóstica, que destaca as possibilidades de acesso ao mundo vivido do outro, em sua experiência subjetiva e produção simbólica. Em segundo lugar, a dimensão terapêutica, na qual a técnica favorece uma apropriação da experiência por parte do sujeito que pode, então, assumir uma postura ativa em sua reconfiguração. Na conclusão, destaca a relevância do conhecimento clínico calcado na subjetividade do paciente, a mudança de olhar sobre si mesmo que a técnica proporciona, a postura ativa do sujeito no processo de mudança e o paradoxo entre imaginação e memória.
\end{abstract}

Palavras-chave: técnica de ancoragem, hipnose, dor crônica, subjetividade, sujeito

\section{Hypnosis, Chronic Pain, and Anchoring Techniques: Therapy from the Inside Out}

\begin{abstract}
This paper addresses the anchoring technique in hypnosis and focuses on the subject as an active participant in the therapy process. Clinical examples of clients suffering from chronic pain are used to highlight two extremely relevant dimensions of this technique. First, the diagnosis addresses possibilities of accessing the experiences of others in both their subjective experiences and symbolic productions. Second, the technique is used in therapy to encourage subjects to appropriate their experiences and, therefore, actively participate in reconfiguring them. The conclusion states the relevance of clinical understanding founded on client subjectivity, changes in self-awareness brought on by the technique, the active involvement of subjects in the process of change, and the paradox between imagination and memory.
\end{abstract}

Key words: anchoring technique, hypnosis, chronic pain, subjectivity, subject

Os procedimentos designados como técnica de ancoragem, na qual o paciente é induzido a se concentrar numa parte de seu corpo, expressando o que vem à sua mente, não consiste em novidade na prática da hipnose, principalmente no que se refere às demandas de dores crônicas. A obra de Milton H. Erickson, criador da técnica, (Erickson, 1983, 1986; Erickson \& Rossi, 1979), nesse sentido, é de grande importância, não apenas por destacar várias possibilidades de aplicação, mas, sobretudo, por enfatizar a participação do paciente como sujeito da terapia. Rompendo com a perspectiva comum na hipnose da técnica como algo que se impõe de fora para que o paciente obedeça, este autor, inspirado numa ótica humanista e pragmática (Neubern, 2009a), destaca que o contexto terapêutico deve favorecer a emergência das potencialidades do sujeito para que este, a partir de seus próprios recursos, possa mudar a experiência das dores que o acometem. Ao voltar suas atenções sobre o próprio corpo,

1 Este trabalho deriva do projeto de pesquisa "Hipnose, subjetividade e dor crônica: construindo o contexto terapêutico", aprovado pelo Comitê de Ética em Pesquisa (CEP/UNB). Todas as condições éticas para pesquisa com humanos foram obedecidas, inclusive a assinatura do termo de consentimento livre e esclarecido. Os nomes das pacientes são fictícios, para a preservação de sua identidade. Agradecimentos ao Centro de Atenção e Estudos Psicológicos (CAEP) pela estrutura e apoio prestados a esta pesquisa e pelo Departamento de Pesquisa e Pós-Graduação pelo apoio em equipamentos.

2 Endereço para correspondência: Campus Universitário Darcy Ribeiro, ICC Sul, Instituto de Psicologia, Departamento de Psicologia Clínica, Brasília, DF, CEP 70910-900.E-mail: mneubern@hotmail.com o sujeito teria condições de perceber sua experiência de outra forma e, devido ao acesso proporcionado pela experiência do transe, modificar suas relações com a constituição subjetiva de sua dor em termos de significados, emoções e referências de mundo (Erickson, 1983).

No entanto, a concepção da ancoragem encontra na atualidade consideráveis barreiras, possivelmente, pelos seguintes motivos. Primeiramente, embora Erickson houvesse descrito minuciosamente seu trabalho, não demonstrou maiores interesses em explicar e teorizar sobre suas propostas, cuja complexidade trouxe muitas dificuldades para as sistematizações posteriores desenvolvidas por seus discípulos (Zeig \& Geary, 2001). Nesse sentido, concebe-se que a complexidade de seus pensamentos, as rupturas constantes que fazia quanto aos paradigmas dominantes na prática clínica e a perspectiva qualitativa que conferia à pesquisa da hipnose tenham contribuído para que seu trabalho permanecesse mais ligado aos psicoterapeutas e suas práticas e encontrasse pouco espaço nos grandes centros de pesquisa, principalmente nos EUA (Neubern, 2009a). Assim, face a um pensamento de difícil apreensão e pouco desenvolvido como retórica comunicativa nas academias científicas, as técnicas hipnóticas da ancoragem, no sentido original tecido por Erickson, permaneceram entre a obscuridade e o esquecimento, sendo raramente retomadas de forma sistemática ou como objeto de pesquisa.

Em segundo lugar, o próprio ímpeto tecnicista contemporâneo, no qual existe uma primazia da técnica eficiente em 
detrimento da reflexão e do sujeito (Neubern, 2005) contribui para que a dimensão subjetiva dos processos hipnóticos não seja considerada como importante condição dos processos terapêuticos ligados à dor. A ênfase das pesquisas geralmente recai sobre populações (Jensen \& Patterson, 2006), modelos de intervenção (Turk, Swanson, \& Tunks, 2008) e problemas específicos (Liossi, 2006; Nogueira, Lauretti, \& Costa, 2005) sem conceber importantes dimensões qualitativas do processo terapêutico como o contexto em que as intervenções ocorrem, a forma como terapeuta e paciente geram sentido sobre as mesmas e como se dá o processo de mudança em sua riqueza e diversidade. Tais propostas, que fundamentam suas avaliações na emissão de respostas a instrumentos e não na complexidade do processo, acentuam a dicotomia entre mente e corpo e a ideia de que o corpo é uma instância impessoal sem subjetividade. Logo, a técnica assume o formato de um medicamento, ou seja, uma instância externa, produto do saber científico e ministrada por algum representante desse saber que atuará sobre o corpo da pessoa sem que esta assuma qualquer participação no andamento da terapia.

Desse modo, o presente trabalho possui o objetivo de retomar a discussão sobre as técnicas de ancoragem em dores crônicas, destacando a condição do sujeito como participante ativo no processo terapêutico. Ao mesmo tempo em que tal objetivo busca favorecer visibilidade para uma técnica com grande importância para tais demandas clínicas, ele busca resgatá-la em seu sentido original, segundo o qual, mesmo em transe, o paciente deve assumir sua condição de sujeito para que a terapia efetivamente aconteça (Erickson, 1983, 1986). Com o intuito de destacar a relevância dessa técnica, serão desenvolvidos tópicos que enfatizam tanto suas possibilidades diagnósticas em termos de acesso ao mundo de experiências do outro, como de suas possibilidades terapêuticas em situações de dores crônicas. No entanto, visando-se a uma compreensão mais clara da condição de sujeito, serão utilizados, num esforço inicial de articulação teórica, referenciais fenomenológicos que se fundamentam na experiência de mundo do sujeito (Casey, 1976/2000a; 19872000b; Csordas, 1997; Merleau-Ponty, 1945/2008) e na produção simbólica de sua subjetividade (Gonzalez Rey, 2007; Neubern, 2009b). Assim, tanto as perspectivas de corpo, espaço e tempo vividos que se referem a essa dimensão experiencial, como as de sujeito e sentido subjetivo, oriundas desses teóricos contemporâneos da subjetividade, serão aproximadas de maneira a se oferecer algumas referências que possibilitem a compreensão dos processos que se desencadeiam e são apropriados pelo sujeito a partir da ancoragem.

Tais propostas serão aqui desenvolvidas a partir de breves ilustrações clínicas de pacientes portadoras de dores crônicas que foram voluntárias de um projeto de pesquisa, conduzido pelo autor deste trabalho, sobre hipnose e dor crônica. Cada paciente submeteu-se a sessões semanais de hipnoterapia (Erickson \& Rossi, 1979), com variado número de sessões, que ocorreram na clínica escola de uma universidade e foram conduzidas, filmadas e interpretadas numa ótica qualitativa de pesquisa (Gonzalez Rey, 2005; Neubern, 2009c) pelo autor do trabalho. Vale ressaltar ainda que, pelos limites de espaço deste trabalho, não serão possíveis maiores esclarecimentos sobre boa parte dos princípios técnicos da hipnose aqui utilizada que, porém, podem ser encontrados nas obras citadas ao longo do texto (Erickson \& Rossi, 1979; Erickson, 1983, 1986).

\section{Ancoragem e acesso ao outro}

Uma vez que o corpo consiste na morada existencial do sujeito (Merleau-Ponty, 1945/2008), a proposta de fazer com que um paciente crônico se fixe sobre alguma parte de seu corpo pela técnica de ancoragem pode se constituir em importante forma de acesso a seu mundo de experiências vividas. Esse mundo, que antecede a consciência deliberada e racional, não se constitui como um mundo natural onde a cultura se inscreve (Csordas, 1997), mas num universo imaginário e, por vezes, inconsciente que é perpassado por personagens, imagens, símbolos sócio-culturais e sistemas de crenças, mas que são apropriados e se produzem de forma legítima pelo sujeito em sua singularidade (Morin, 1991). Assim, a emergência desse mundo por meio do transe inserido numa relação terapêutica pode permitir, tanto ao paciente como ao terapeuta, uma compreensão abrangente sobre a experiência da dor crônica em termos das imagens, símbolos e relações sociais que nela se configuram e geram sentido, como também das possibilidades de mudança aí presentes (Neubern, 2009a). Sem colocar em pauta uma discussão sobre a causalidade da dor, tal emergência pode mostrar de forma pertinente as realidades criadas pela dor crônica: as relações e inserções sociais que se criam em torno dela, as missões familiares, os sistemas de crenças, projetos de vida, o uso do dinheiro, tudo isso perpassado por intensa produção simbólica do sujeito em seu mundo.

Quando Dona Fernanda, 58 anos, entrou em transe pela primeira vez, dentre as oito sessões das quais participou, pôs-se a chorar intensamente ao fixar suas atenções sobre a região do alto da coluna. Embora buscasse terapia devido às dores intensas de uma artrose no joelho esquerdo, foram as dores do alto da coluna sobre as quais ela mesma se fixou, o que trouxe a visualização de uma série de imagens de seus familiares em seu mundo de experiências. Ao ser interpelada pelo terapeuta se lhe surgia alguma imagem quando pensava nessa região, Fernanda disse que vinha à sua mente um grande pacote e que dentro dele havia seus filhos, irmãos, sobrinhos, enfim, um grande número de pessoas de sua família que dependiam de sua ajuda financeira e pessoal e que tais pessoas não poderiam passar sem sua ajuda. Aos poucos percebeu-se aqui um considerável conflito no qual o peso desse pacote sobre seus ombros impedia que ela se movimentasse pela vida e realizasse seus projetos pessoais, como casar-se de novo, mudar de cidade e concluir sua graduação.

Nesse sentido, a imagem desse grande e pesado pacote sobre os ombros era profundamente pertinente quanto à sua situação naquele momento, uma vez que Fernanda se esforçava para cumprir o papel de boa filha, algo legado por sua família de diferentes formas e que implicava no sacrifício de si mesma em prol do bem-estar dos demais. Sob a influência dessa missão, foi ela quem arcou com as despesas e cuidados do pai antes da morte deste, prometendo-lhe cuidar da mãe e dos irmãos, que eram em número de cinco; era ela quem se ocupava dos cuidados diretos da mãe e de uma série de despesas da irmã que sempre a perseguiu e menosprezou; era 
ela quem assumia as contas de seus filhos já adultos e que, vez por outra, precisava ajudar alguns sobrinhos em apuros financeiros. Logo, a perspectiva de tomar outros rumos com o casamento, indo para outra cidade, e investir em si mesma parecia soar, em termos da produção de sentidos subjetivos, como uma espécie de desobediência a tal missão e à promessa feita ao pai ainda moribundo no hospital.

Como ilustrado nesse caso, a técnica da ancoragem proporciona uma espécie de compreensão diagnóstica sobre a experiência da pessoa, principalmente a partir da produção imaginária que dela emerge. Obviamente, semelhante processo pode ser útil para subsidiar compreensões diagnósticas formais, estabelecendo distinções significativas entre estruturas clínicas que, à primeira vista, parecem muito semelhantes, como as diferentes formas de depressão. Uma pessoa com uma estrutura de fundo mais voltado para a melancolia (Binswanger, 1960/2005) costuma descrever suas relações com as imagens como se elas trouxessem uma carga de morbidez acentuada que antecede o próprio eu, ameaçando sua existência e integridade de maneira a atravessá-lo. O peso que daí advém é descomunal, mas é diferente do que ocorre com Fernanda, cujas imagens não a imobilizam de forma irresistível, nem a atravessam de maneira a produzir a experiência de espaço escuro (Merleau-Ponty, 1945/2008), onde o sujeito não mais divisa sua distância e fronteiras com relação aos outros e as imagens de seu mundo vivido. Embora possuísse alguns sintomas de depressão, a paralisação que esta paciente vivenciava possuía uma qualidade muito distinta, uma vez que seu eu se apresentava inteiro, não sendo invadido por uma experiência mórbida, de maneira que era possível divisar uma distância vivida e uma separação com respeito ao grande pacote. Em suma, seu problema se apresentava muito mais ligado à esfera do dever que lhe fora imposto, mesmo que parecesse injusto, do que a uma experiência do sentir que transborda fronteiras e ameaça o afogamento do eu do sujeito (Martins, 2007).

No entanto, além de uma compreensão estrutural como esta, a experiência das imagens pode proporcionar uma compreensão abrangente sobre o sujeito e a produção de sentidos particulares que se configuram em torno de seu problema (Csordas, 1997). Contudo, devem-se destacar algumas condições importantes para que as imagens possam oferecer subsídios para tal forma de abordagem da experiência dos sujeitos. Primeiramente, na perspectiva aqui discutida (Csordas, 1997; 2002), as imagens são vividas enquanto processos da corporeidade das pessoas, pois consistem numa espécie de abertura dos arquivos vividos da experiência do sujeito que é incrustado no próprio corpo, que é sua morada existencial. O paciente, portanto, não se limita a assistir imagens, como se visse um filme externo a seu mundo, mas as vive e sente de maneira a estabelecer uma relação performática com as mesmas. Em segundo lugar, as imagens não consistem apenas em experiências visuais (Sartre, 1940/2005), mas podem envolver outros tipos de experiências corpóreas e sentidos físicos, como o peso sentido por Fernanda sobre o pacote em seus ombros. Sua vivência era tão concreta que fazia com que a paciente se curvasse e sentisse muita dor, fosse pela carga de sua missão, fosse pelo fato de ser habitado por vários personagens de sua família.
Em terceiro lugar, as imagens não consistem em meras respostas a sugestões diretas do terapeuta, uma vez que se referem a uma produção espontânea do sujeito, que por vezes surge fora de sua deliberação racional e são pertinentes com respeito a seu cenário de vida naquele momento. Elas trazem em si uma complexidade muito superior à de uma lógica linear típica das deliberações simplistas e intencionais, já que envolvem uma multiplicidade de sentidos e emoções, de dramas relacionais e familiares, como de sistemas e práticas sociais de uma cultura. Não é sem razões que a hipnose aqui discutida (Erickson \& Rossi, 1979) não implica em ordens diretas a serem executadas por um paciente passivo, mas em metáforas, figuras de linguagem e paradoxos que possuem uma coerência simbólica com os temas vividos pelos pacientes e os convidam a atuarem como sujeitos no processo terapêutico, ou seja, apropriando-se de tais formas de sugestão de maneira a produzirem a emergência de suas próprias imagens e criarem uma nova forma de se posicionar e relacionar com elas. Isso favorece que tais imagens, nesse processo relacional, sejam marcadas por um teor emocional que as legitima como produções próprias do sujeito, que remetem a sentidos que são coerentes com seu cotidiano, mas que possuem certa autonomia quanto a suas deliberações, intenções e expectativas, podendo mesmo contrariá-lo, apontando para facetas da vivência que ainda não percebe, aceita ou compreende.

Nessa perspectiva, é possível conceber que as imagens, por se constituírem como aberturas do arquivo vivo que se incrusta no corpo vivido, permitem uma compreensão fenomenológica significativa sobre as pessoas, uma vez que remetem a dimensões centrais da existência humana, como o corpo, o tempo, o outro e o espaço como processos vividos (Ellenberger, 1958/2004). No caso aqui discutido, a imagem do pacote enraizado no alto da coluna remete a um conjunto de sentidos complexos do cenário de vida de Fernanda. $\mathrm{O}$ pacote é algo grande, incômodo e difícil de ser carregado, mas com o qual sente a obrigação de carregar, mesmo que isso implique em grandes sacrifícios. Esse mesmo pacote é habitado por pessoas que pesam e precisam ser carregadas, numa condição que, apesar de envolver afeto e carinho por serem pessoas próximas, implica numa vivência de exploração por parte do outro que não aprendeu a se cuidar e se orientar pela vida e precisa contar com o sacrifício da paciente.

Há aqui um considerável desequilíbrio na questão do cuidar (Binswanger, 1935/2008), uma vez que a paciente se vê obrigada a devotar-se aos outros de forma intensa e incondicional, sem receber a consideração e os cuidados que sua própria condição exigiam. Tais processos fazem com que sua vivência de corpo seja a de um corpo dolorido e pesado, que sente na própria carne o peso das obrigações e possui grandes limitações para se movimentar, tanto em termos físicos, como de se mover por sua própria existência. Assim, o mundo não se mostra à primeira vista como algo estreitado, como seria o caso da vivência de alguns esquizofrênicos (Minkowski, 1936/2006, 1933/2005), já que possui muitos atrativos capazes de lhe fazer sonhar com projetos como o casamento e a conclusão de sua graduação; entretanto, a paralisação vivida por seu corpo dolorido a impede de desfrutar esse mundo, o que lhe traz um intenso sofrimento. Nessa mesma linha, apesar de o futuro não ter deixado de 
existir, suas possibilidades se tornam mais escassas, já que o peso, a dor e a paralisação do corpo, com todos os sentidos que os perpassam, a impedem de se mover para frente e concretizar seus projetos.

Com efeito, a ancoragem, pelo tipo de acesso que proporciona ao mundo do outro, necessita ser pensada numa ética do humano de maneira a se evitar qualquer tentativa de reduzi-la a seu caráter instrumental. $\mathrm{O}$ conhecimento que dela pode emergir não remete a uma interação fria e pretensamente neutra com um objeto, mas de uma relação que considera a condição do outro em seu mundo, buscando compreendê-lo a partir de suas próprias referências. Isso implica em considerar que, malgrado as possíveis objetivações das informações que emergem desse contato, não existem informações em si, porque elas remetem ao mundo desse sujeito e é nesse mundo que ganham seus sentidos. A técnica, portanto, não deve ser pensada como algo de fora que se impõe ao sujeito, pois isso pode facilmente se transformar numa forma de invasão, ao invés de terapia. Ela precisa ser pensada e qualificada na relação com ele e para ele de maneira que este sujeito se aproprie das realidades que ela cria e possa cumprir seu papel no processo terapêutico.

\section{Ancoragem e o Sujeito da Terapia}

Uma das questões mais importantes na discussão sobre o uso da hipnose em dores crônicas, que também abrange a ancoragem, refere-se à eficácia terapêutica de suas técnicas. O princípio comum aqui adotado considera que a técnica só ganha vida em um processo relacional em que os protagonistas, terapeuta e paciente, são engajados emocionalmente e cumprem seus respectivos papéis nessa relação: enquanto ao terapeuta cabe a facilitação do processo, com a participação ativa na produção de um contexto de possibilidades, ao paciente cabe a tarefa de tornar-se sujeito do processo, tornando-se agente ativo na transformação de sua própria experiência (Erickson, 1983). É nesse sentido que se destaca que a técnica, em si mesma, é um instrumento cego e inerte que, malgrado suas possibilidades, depende profundamente da participação dos protagonistas que se engajam no processo terapêutico. Torna-se, assim, possível considerar que uma reação catártica, que comumente ocorre na ancoragem de pacientes com dores crônicas, não necessariamente implica em mudanças significativas se o terapeuta não se utiliza dela para a criação de uma situação terapêutica e se o paciente não a aproveita para mudança de significados e posturas diante de sua experiência. $\mathrm{O}$ mesmo vale para as rememorações que, caso não cumpram tais condições, podem se transformar em mera coleção de imagens que em nada se aproveita ou até num processo desorganizador que prende o paciente a experiências dolorosas.

Desse modo, vale destacar que, caso o contexto favoreça, o paciente, mesmo estando em transe, assume a condição de sujeito em seu processo de terapia. Por um lado, quando o terapeuta se utiliza de um modo relacional permissivo e de uma linguagem metafórica e indireta (Erickson \& Rossi, 1979), ele oferece várias estruturas de significados (frames) que permitem que o paciente as processe ou vivencie de acordo com suas próprias demandas e referências internas e recrie suas emoções, sentidos e atitudes de forma ativa. $\mathrm{O}$ sujeito não produz uma resposta a um estímulo sugestivo, mas ele se apropria da história e tece nova rede de significados, referências e emoções que poderão ser de grande valia para a modificação de sua experiência de dor. Logo, a descrição pormenorizada, durante o transe, de um rio que flui suave e firmemente, contornando seus obstáculos e levando vida a regiões, matas e animais pode ser apropriada por um paciente como alguma coisa que desbloqueia seu corpo, irriga seus membros e traz vitalidade a partes do corpo por ele sentida como se fossem desenergizadas. É curioso notar que, quando o sujeito efetiva tal apropriação, tais intervenções comumente conseguem promover mudanças relevantes na experiência das dores dos sujeitos, seja por aliviá-las, reduzi-las ou até eliminá-las.

De outra parte, o contexto hipnótico favorece a emergência de um eu inconsciente que permite que o sujeito esteja em transe, mas permaneça ativo no que se refere à transformação de sua experiência (Neubern, 2009a). Quando o mundo de experiências vividas ou inconsciente vem à tona por meio do transe, ele não se apresenta como uma máquina impessoal e determinista que se impõe ao paciente, pois, apesar de seus automatismos, ele se refere a um mundo pessoal, onde a noção de eu pode assumir variadas formas de expressão. No entanto, apesar desse eu poder ser simbolizado como um personagem desse mundo imaginário ou um objeto desse mundo, como ocorre nos sonhos (Rossi, 2007), ou a de um alter, como no caso das personalidades múltiplas (Hacking, 1999), ele assume a condição de um agenciador do processo terapêutico, ou seja, alguém que negocia e estabelece um contrato com o terapeuta e promove a criação da experiência. Longe de ser pensado como uma entidade fixa, substancializada e reificada, deve ser concebido como um agente que emerge no transe para se relacionar com o terapeuta: é com ele que o terapeuta conversa e negocia, é ele quem apresenta as imagens, quem traz as lembranças, quem produz o fenômeno hipnótico, resgata aprendizagens antigas e, enfim, promove a transformação da experiência. Desse modo, quando o paciente em transe escuta contar histórias sobre as experiências infantis, destacando formas de aprendizados e sensações aí presentes, é o eu inconsciente quem traz à tona as experiências da própria infância do paciente, de maneira a conduzi-la de acordo com os rumos terapêuticos que podem existir nesse conto que sejam pertinentes para a demanda em questão.

Tendo em vista semelhante fenômeno, uma das primeiras e mais importantes medidas para a aplicação da técnica de ancoragem é a busca da criação do transe como uma experiência segura e protegida, sobretudo, devido ao risco que alguns pacientes correm de ficarem fixados em experiências traumáticas ou negativas. $\mathrm{O}$ eu inconsciente deve ser acionado no sentido de ajudar o paciente, de início, a se ancorar em experiências construtivas, prazerosas, suaves, enfim, que permitam uma sensação de segurança diante de seu próprio mundo de experiência. Sendo acionado dessa forma, o eu inconsciente pode proporcionar experiências capazes de promover maior sensação de poder e autonomia ao paciente, facilitando a emergência de sua condição de sujeito, como também promover a reconstrução de sua identidade. Em outras palavras, o oferecimento de maior visibilidade a tais 
experiências por meio de imagens e memórias que falam fortemente ao visual, ao sentir no corpo algo diferente do sofrimento marcante e habitual, e que ainda é acompanhado de metáforas que redefinem a forma de gerar sentidos, permite a desconstrução do conjunto de significados e percepções que servem de base para sua identidade. Passa, então, a haver a possibilidade de que o paciente se sinta em condições de lidar melhor com suas configurações de dor, de possuir maior autonomia e poder de ação junto às mesmas, de modo a transformá-las em sua emocionalidade e produção de sentido.

Quando Dona Clarisse, 58 anos, buscou terapia sob intensas dores de uma artrite reumatóide, suas experiências iniciais de transe faziam emergir muitas cenas de maus tratos vividos em sua família durante a infância, que implicavam tanto agressões físicas, sexuais, xingamentos e mentiras. Seu processo hipnoterápico durou 30 meses, com sessões semanais. Percebendo um sofrimento que inundava a experiência da paciente como uma torrente, o terapeuta induziu-a, por meio de contos sobre experiências infantis, a se concentrar nas brincadeiras de sua infância, quando então se viu muito pequena brincando com outras crianças e uma bola à beira de um rio. Aproveitando-se desse relato, o terapeuta utilizou, de forma cadenciada e repetitiva, suas próprias palavras e expressões para ancorar uma série de sensações e percepções daquele cenário em seu corpo: o calor agradável do sol no rosto, o riso das crianças reverberando, a brisa prazerosa beijando suavemente seu corpo, a beleza do rio fluindo diante de seus olhos e a alegria contagiante em todo o corpo de correr atrás da bola com os outros, mesmo quando o brinquedo foi levado pelo rio. Suas expressões físicas naquele momento apresentaram uma descontração corpórea acentuada, de maneira que a tensão e a ansiedade foram substituídas por calma e relaxamento e que seu semblante anteriormente choroso e sofrido cedeu lugar a uma expressão risonha e leve.

A importância desse momento se deu, além de outras razões, pela criação de um espaço em seu mundo que não fosse invadido e contaminado pelas ondas de sofrimento, $\mathrm{o}$ que destacava para ela que, malgrado a existência de muitas experiências infelizes, dolorosas e sufocantes, ela também tinha vivenciado experiências de alegria, leveza e prazer, tendo tido também importantes momentos como criança. A delimitação de semelhante território em seu mundo proporcionou-lhe uma sensação de diferença significativa sobre si mesma, uma vez que podia identificar em si algo que sempre desejou (ser uma criança como as outras), mas julgava nunca ter vivido. De posse dessa experiência, não foi difícil para que Clarisse, sob sugestão do terapeuta, ignorasse os gritos das brigas do pai e da mãe que vinham de sua casa e continuasse a aproveitar aquele momento especial à beira do rio.

Como essas imagens traziam em si as temáticas simbólicas vividas pela paciente, a mudança que pôde implementar nas mesmas coincidiu com mudanças significativas em sua própria vida. Além do abandono da posição conflituosa que adotava na comunicação com seus pais, relatou ter passado a enxergá-los como eram no momento atual, ou seja, pessoas que erraram muito, mas que agora estavam velhas e doentes. A vivência de seu corpo tornou-se bem mais leve como se tivesse deixado um grande fardo para trás e a relação com os outros, antes sempre na defensiva, tornou-se mais leve, suave e tranquila. Voltou a alimentar projetos de futuro, a se locomover pela cidade sozinha e suas dores, embora continuassem a existir, foram reduzidas de modo significativo. Isso leva a conceber que a decisão de não voltar para casa remeteu não apenas a uma delimitação entre os dois espaços vividos - o da criança que brinca e o da criança que é maltratada - mas também a uma condição ativa que lhe permitiu o movimento e a opção de não ir até lá e permanecer no espaço seguro e protegido. Dito de outro modo, a paciente saiu de uma posição de prisioneira, de cruel submissão ao sofrimento para a de sujeito, na qual não se encontrou mais sob o império do maltrato de maneira a poder optar por uma posição mais confortável na experiência onde estava e se recusar a voltar para a experiência que a fazia sofrer.

Entretanto, longe de pensar tais processos estritamente sob uma ótica de desenvolvimento de padrões, estes como processos objetivados e observáveis apenas de fora, é necessário que o terapeuta conceba tais ações como uma apropriação do sujeito. Talvez impulsionado pela ação do eu inconsciente que emerge no transe (e possivelmente este seja um diferencial da hipnose quanto a outras terapias), o paciente se torna sujeito ao aprender a se movimentar e atuar sobre seu mundo de experiência, repetindo à sua maneira o que a ancoragem proporciona. Não é ele, por si mesmo, quem traz as memórias que farão a diferença, como no caso da paciente; mas ele pode absorver, assimilar, degustar as sensações que tais memórias proporcionam. Ele também não traz o sofrimento incrustado em seu corpo vivido; mas pode aprender a se distanciar dele, a dividi-lo, a circunscrevê-lo a uma determinada região, a não ser hipnotizado pela voz com a qual esse sofrimento tenta envolvê-lo. Pode mesmo perceber que é possível deixar de alimentá-lo, levando-o ao enfraquecimento ou a um tamanho menor e mais leve. Pode até se dar conta de que as vivências do tempo durante o sofrimento são passíveis de alteração e que suas atenções e tempo podem se fixar em outros tipos de experiência. Em suma, tais ações consistem em mudanças na própria simbolização das experiências que, todavia, não são percebidas instantaneamente, geralmente ocorrem num nível inconsciente e além de sua intencionalidade.

\section{Ancoragem, Imaginação e Rememoração}

Por sua vez, o processo de reconfiguração da experiência passa, necessariamente, pela performance que o paciente desempenha, enquanto sujeito, entre duas potências do mundo imaginário e inconsciente - a imaginação e a rememoração (Casey, 1976/2000a, 1987/2000b). Longe do que uma leitura superficial possa sugerir, a imaginação não consiste numa criação deliberada de imagens, mas num processo espontâneo que acorre à experiência do sujeito e que possui considerável relevância terapêutica por permitir o movimento, a ação e, dentro de certas condições, a possibilidade da escolha. Trata-se de uma forma de ação do sujeito ou do eu inconsciente no mundo vivido. A materialidade da imaginação envolve plasticidade de maneira a facultar a ação do sujeito que pode moldá-la, em certa medida, de modo a modificar sua relação com a própria constituição do mundo de experiência onde ele se insere. Por outro lado, a emergência das memórias vividas envolve um 
conjunto de experiências que se impõem ao sujeito colocando-se muito pouco disponíveis e influenciáveis à ação direta do sujeito, principalmente quando envolvem rememorações de sofrimento. Na vivência de muitas pessoas, as memórias abrangem um reino de experiências do que já aconteceu e não volta mais, nem pode ser modificado, já que não é possível voltar no tempo. Acompanhadas por toda uma transformação de mundo (Sartre, 1963) promovida por emoções como a ansiedade e o medo, tais memórias constrangem o sujeito sob o grilhão daquilo que parece irremediável, do que se impõe a ele de modo determinista e que, a princípio, não oferece opções e que permanece irremovível aos apelos da vontade. Em meio ao aparente paradoxo entre a fluidez da imaginação e o determinismo da rememoração, muitos pacientes portadores de dores crônicas sentem-se, de início, paralisados e impotentes por não vislumbrarem perspectivas de solução.

No entanto, as experiências mobilizadas pela ancoragem podem favorecer relações muito frutíferas entre tais potências da subjetividade, como pode ser ilustrado no caso de Dona Yvonne, 50 anos, que buscou a terapia em função das diversas dores provenientes de lúpus recém diagnosticado. Seu processo hipnoterápico durou 20 meses, com sessões semanais. Tendo vivido muitos anos sob intensa depressão, ela relatava uma história de muitos maus tratos na família envolvendo apelidos racistas, surras, trabalhos forçados e desqualificações constantes, afirmando ainda que sua vida era um rosário de sofrimento. Curiosamente, Yvonne possuía muita dificuldade em se olhar de frente no espelho, o que era seguido de esquivas, muito choro e várias justificativas sobre sua história de castigos e humilhações. Face a semelhantes construções tão negativas sobre si mesma e seu mundo de experiências, não foi sem razões que as primeiras experiências de transe foram marcadas por consideráveis torrentes de memórias negativas que exigiram do terapeuta muita utilização da ancoragem.

Numa das sessões, quando já havia adquirido ganhos significativos na terapia, o terapeuta procedeu a um trabalho minucioso de ancoragem por várias partes do corpo: este era um grande jardim e, em cada parte, ela poderia sentir a terra, escolher os tipos de flores e plantas, fertilizar, aguar, conversar com as plantas e deixar que o sol e a natureza fizessem o seu trabalho. O procedimento, que foi elaborado de acordo com seu gosto por plantas, promovia experiências muito prazerosas que eram relatadas pela paciente, até que o processo chegou à sua cabeça. Nesse instante, pôs-se a chorar, relatando ter regressado aos maus tratos de seu pai e de sua família, numa sequência de memórias muito árdua, persistente e difícil de ser quebrada. Então, o terapeuta utilizou-se da técnica de levitação de braço ${ }^{3}$ (Erickson, 1961) com o intuito de fixar sua atenção nas boas experiências daquele braço do jardim e retomar as sensações de paz e satisfação que vinha sentindo no transe. Enquanto ela fixava sua atenção no braço, perceberia que sua cabeça seria

3 Técnica na qual o terapeuta suspende ou pede que o sujeito suspenda o braço durante o transe (Erickson, 1961). Ao fixar sua atenção no braço, o terapeuta sugere que este possui um funcionamento distinto quanto ao resto do corpo, o que pode gerar a sensação de que o braço se torna independente do corpo e da vontade do sujeito. Essa técnica é útil para aprofundar o processo dissociativo e auxiliar na produção de diferentes fenômenos hipnóticos, como anestesia. isolada do resto do corpo e que ela não precisaria prestar atenção ao tratamento que seria feito nessa parte, já que o importante era o resto do corpo relaxado e em paz. Curiosamente, Yvonne relatou ter visto um homem trajado como enfermeiro se aproximar, colocar uma espécie de bucha em seu cérebro e assimilar boa parte de uma substância negra e pegajosa que parecia estar ali há muito tempo. Para ela, que frequentava centros espíritas, tratava-se da intervenção de um mentor espiritual que teria aparecido para auxiliar o processo de sua terapia.

É interessante notar como o jogo entre imaginação e rememoração apareceu nesses relatos de Yvonne. Num primeiro momento, após uma sequência de imagens prazerosas do jardim, as memórias surgiram ligadas à cabeça como um turbilhão de experiências negativas que inundava seu mundo a ponto de paralisá-la e deixá-la impotente. As memórias em si mesmas, como acontecimentos do imaginário, não poderiam ser modificadas, mas poderiam ser contidas em alguma região da mente para serem reconfiguradas em suas produções de sentido. Nesse ponto, a ancoragem foi pertinente por permitir que a imaginação contivesse o turbilhão de processos negativos numa região do corpo - a cabeça - de maneira a não contaminar todo o mundo de sua experiência, simbolizado aqui como o resto do corpo. Essa forma de continência do sofrimento a um espaço vivido no corpo colocava-a novamente numa postura ativa, já que, mesmo tendo recebido a sugestão, era seu eu inconsciente quem produzia esse isolamento, como era ele quem permitia que se fixasse e desfrutasse da ancoragem prazerosa nas outras regiões do corpo. De certa forma, sua imaginação permitiu um reequilíbrio da experiência vivida, ao estabelecer territórios distintos no corpo entre as experiências de sofrimento e as experiências de paz, prazer e satisfação.

No entanto, a imaginação, enquanto ação do eu inconsciente no mundo imaginário, proporcionou ainda duas intervenções da mais alta importância terapêutica no processo de Yvonne. Primeiramente, ela permitiu que as memórias de sofrimento torrencial que a acometiam fossem simbolizadas como uma substância negra incrustada no cérebro. Ao efetivar isso, ela não só lhe conferia uma série de significados, circunscrevendo-a na materialidade de algo com forma, cor e textura, ou seja, tornava-a concreta, como também a colocava na condição de um objeto passível de ser manipulado. Em segundo lugar, aliando-se a suas crenças espíritas, a imaginação trouxe uma figura espiritual (um ser do além) que pudesse manusear e tratar das memórias materializadas na substância negra. Dito de outro modo, um ser espiritual, imbuído dos conhecimentos e poderes do outro mundo, esteve presente em seu mundo de experiências vividas e interveio de modo a trabalhar, tratar, cuidar daquela massa escura que, para ela, talvez dificilmente pudesse ser tratada por outras vias. O que parecia ser impossível, tornava-se assim viável de maneira que agora ela enxergava a possibilidade de ver as coisas sob outro prisma.

Todo esse processo, acompanhado por outras intervenções terapêuticas (Erickson \& Rossi, 1979), possibilitou que Yvonne passasse por mudanças significativas quanto às configurações sobre si mesma e seu mundo de experiências. Conversando com amigos e parentes, ela começou a resgatar outras memórias de sua infância e mocidade, 
nas quais aparecia brincando e aprendendo muitas coisas, sendo um personagem ativo que se divertia, mas também passava por momentos difíceis. Ao se referir à sua história, ela reconhecia que havia tido muitas experiências infelizes, mas as experiências construtivas de alegria, amizade, carinho também não haviam faltado. Tais mudanças eram acompanhadas por novas produções imaginárias durante $o$ transe que simbolizavam com pertinência novas produções de sentido sobre si mesma e seu mundo. Numa delas, via seu corpo cheio de buracos que eram remendados pelas flores do jardim que cultivava, o que acontecia sob uma sensação de muito alívio. Noutra, via-se num hospital espiritual em que os enfermeiros ajudavam-na a se olhar no espelho, o que, agora, parecia ser muito mais fácil. A imagem de si mesma era reconstituída por uma experiência altamente significativa (as flores) de tal maneira que, a partir desses momentos, ela poderia olhar para si mesma de modo muito mais tranquilo, observando seu corpo (morada de suas experiências vividas) como um todo.

Tanto no transe como nos sonhos, as memórias de suas brincadeiras na roça, no rio, na pesca, no roubo de frutas e nas lutas com os irmãos haviam voltado, trazendo-lhe uma grande sensação de bem-estar. Por meio da imaginação, o resgate de novos tipos de memória, com uma qualidade distinta daquelas que eram sempre reconhecidas pela depressão, reorganizou seu mundo de experiências, de maneira que ela passou, como grande parte das pessoas, a dar visibilidade ao sofrimento, mas também a um série de momentos de alegria, crescimento e afeto. Com sua história vivida, enquanto processo encarnado, significativamente modificada, suas dores foram em muito reduzidas e os sintomas da depressão perderam sua razão de ser. Yvonne sentia-se mais leve e podia olhar novamente para o futuro que há muito tempo havia deixado de existir.

\section{Considerações Finais}

Ao se buscar oferecer maior visibilidade às técnicas de ancoragem em termos da vivência dos sujeitos, um dos primeiros pontos que se destaca é o conhecimento que essa técnica pode propiciar quanto à diversidade e riqueza do mundo do sujeito. Nesse sentido, ela é de grande valia por apontar para um conhecimento clínico calcado em sua subjetividade, referindo-se à sua produção simbólica e emocional de corpo, tempo e espaço, como também às formas de relação que o sujeito desenvolve com as pessoas que habitam esse mundo. Rompendo com a perspectiva de um diagnóstico externo, cujos códigos comunicativos se restringem às comunidades científicas e nada têm a dizer aos leigos, tal conhecimento abre possibilidades para uma compreensão de como o sujeito se sente quando é acometido por uma dor crônica, que realidades se criam em seu mundo e os caminhos que podem ser traçados rumo à mudança.

Entretanto, ao fazer com que o sujeito se volte para sua própria morada existencial, seu corpo, a ancoragem favorece um novo tipo de olhar sobre si mesmo que, seguindo o rumo de uma terapia, pode levar a uma reconciliação consigo mesmo. Embora Fernanda provavelmente já tivesse pensado sobre o peso de sua missão familiar, a imagem do pacote pesado e difícil de carregar em seus ombros parece trazer, ao mesmo tempo, no contexto terapêutico, o choque de perceber a dor que o grande pacote trazia, como também a necessidade de que algo fosse feito rumo à mudança. Como a terapia se coloca no plano do possível, ela pode se deparar com o pacote, mas se dá conta, aos poucos, de que uma mudança nessa imagem, tão significativa para representar sua vida, pode consistir numa mudança diante de si e de seu mundo. Desse modo, a ancoragem acaba fazendo com que o sujeito se depare com sua própria imagem e daí assuma a responsabilidade sobre si mesmo de modo a poder lidar com aquilo que incomoda, envergonha e perturba, mas também descobrir aquilo que traz prazer, esperança e amor por si.

De outra parte, esse retorno sobre si mesmo precisa ser acompanhado por uma apropriação do sujeito, cujas ações no mundo imaginário, como também no mundo concreto, serão decisivas para que as mudanças sejam efetivas. Embora suas ações sejam precedidas, em certa maneira, pela condução técnica do terapeuta e pela negociação deste com o eu inconsciente, o paciente se torna sujeito quando assume e passa a pontuar uma relação distinta com a experiência de sofrimento. O simples fato de decidir acatar a sugestão do terapeuta de continuar brincando à beira do rio, fez com que Clarisse percebesse que não precisava mais ser arrastada pelos apelos do sofrimento, simbolizado na imagem pelas brigas dos pais dentro de casa. É curioso notar como um momento aparentemente despretensioso como esse coincide com mudanças muito significativas em sua vida, em que a paciente manteve a mesma postura ativa, como na nova postura com relação aos pais, suas locomoções pela cidade, a leveza da relação com os outros, a redução de suas dores e o retorno de perspectivas futuras. Portanto, mesmo que a ancoragem seja ministrada a partir das habilidades do terapeuta, ela precisa de uma apropriação na qual o paciente também passa a mostrar o quanto se torna especialista de si mesmo.

Por fim, a ancoragem traz à tona uma série de zonas de sentido que compõem a experiência do sujeito e remetem a uma complexidade que prima por uma postura de simplicidade, de modo a diferir da superficialidade com a qual frequentemente tais experiências são concebidas. Ao destacar as dimensões da imaginação e da rememoração, ela levanta tanto as possibilidades de ação e movimento como os constrangimentos que se impõem à experiência do sujeito que, por vezes, não oferecem em si mesmos muitas chances de mudança nem cedem facilmente aos apelos diretos da vontade. Concebe-se que um simples processo de visualização talvez não pudesse oferecer muitas perspectivas de mudança à experiência de Yvonne, profundamente marcada pelas rememorações do sofrimento. Todavia, embora não fosse mais possível e talvez nem mesmo ético modificar o que passou, a experiência pôde ser modificada pelo resgate de novas memórias que também passaram a fazer sentido na concepção de si mesma e sua história. Essa reapropriação de seu próprio mundo certamente não pôde modificar o acontecimento incrustado no passado, mas pôde lhe oferecer a chance de tecer um novo começo. Em suma, entre as asas que a imaginação oferece e as raízes que as memórias impõem é que o sujeito pode nascer e ser autor de sua própria história. 


\section{Referências}

Binswanger, L. (2005). Mélancolie et manie. Paris: Puf. (Originalmente publicado em 1960)

Binswanger, L. (2008). De la psychothérapie. In L. Binswanger (Ed.), Introduction à l'analyse existentielle. (119-148). Paris: Minuit. (Originalmente publicado em 1935)

Casey, E. (2000a). Imagining: a phenomenological study. Bloomington: Indiana University Press. (Originalmente publicado em 1976)

Casey, E. (2000b). Remembering: a phenomenological study. Bloomington: Indiana University Press. (Originalmente publicado em 1987)

Csordas, T. (1997). The sacred self. Los Angeles: Universtity of Califórnia Press.

Csordas, T. (2002). Body/meaning/healing. New York: Palgrave MacMillan.

Ellenberger, H. (2004). A clinical introduction to psychiatric phenomenology and existential analysis. In R. May, E. Angel, \& H. Ellenberger (Eds.), Existence. (pp. 92-124). New York: Jason Aronson Book. (Originalmente publicado em 1958)

Erickson, M. (1961). Historical note on the hand levitation and other ideomotor techniques. American Journal of Clinical Hypnosis, 3, 196-199.

Erickson, M. (1983). An introduction to the study and application of hypnosis in pain control. In M. Erickson (Ed.), Healing in hypnosis. (pp. 217-277). New York: Irvington.

Erickson, M. (1986). Symptom based approach in mind-body problems. In M. Erickson (Ed.), Mind-Body communication in hypnosis (pp. 67-202). New York: Irvington.

Erickson, M., \& Rossi, E. (1979). Hypnotherapy: an exploratory casebook. New York: Irvington.

Gonzalez Rey, F. (2005). Pesquisa qualitativa e subjetividade. São Paulo: Thomsom.

Gonzalez Rey, F. (2007). Psicoterapia, subjetividade e pósmodernidade. São Paulo: Thomson.

Hacking, I. (1999). L'âme réécrite. Étude sur La personnalité multiple et les sciences de la mémoire. Paris: Seuil.

Jensen, M., \& Patterson, D. (2006). Hypnotic treatment of chronic pain. Journal of Behavioral Medicine, 29(1), 95-124.

Liossi, C. (2006). Hypnosis in cancer care. Contemporary Hypnosis, 23(1), 47-57.
Martins, F. (2007). O aparentar, o dever, o pensar e o devir. Brasília: Ed UnB.

Merleau-Ponty, M. (2008). Phénoménologie de la perception. Paris: Gallimard. (Originalmente publicado em 1945)

Minkowski, E. (2005). Le temps vécu. Paris: Puf. (Originalmente publicado em 1933)

Minkowski, E. (2006). La schizophrénie. Paris: Payot. (Originalmente publicado em 1936)

Morin, E. (1991). La méthode IV. Les idées. Paris: Seuil.

Neubern, M. (2005). A dimensão regulatória na psicologia clínica: o impacto da racionalidade dominante nas relações terapêuticas. Estudos de Psicologia, 10(1), 73-82.

Neubern, M. (2009a). Psicologia, hipnose e subjetividade. Revisitando a história. Belo Horizonte: Diamante.

Neubern, M. (2009b). Hipnose, dor e subjetividade: considerações teóricas e clínicas. Psicologia em Estudo, 14(2), 303-310.

Neubern, M. (2009c). Hipnose e dor: proposta de metodologia clínica e qualitativa de estudo. Psico, 14 (2), 201-209.

Nogueira, C., Lauretti, G., \& Costa, R. (2005). Avaliação duplamente encoberta da hipnose em fibromialgia. São Paulo Medical Journal, 14(supl 1), 123.

Rossi, E. (2007). The breakout heuristic. Phoenix: The Milton H. Erickson Foundation Press.

Sartre, J. P. (1963). Esquisse d'une théorie des émotions. Paris: Hermann.

Sartre, J. P. (2005). L'imaginaire. Paris: Gallimard. (Originalmente publicado em 1940)

Turk, D., Swanson, K., \& Tunks, E. (2008). Psychological approaches in the treatment of chronic pain patients - when pills, scalpels and needles are not enough. The Canadian Journal of Psychiatry, 53(4), 213-223.

Zeig, J., \& Geary, B. (2001). The letters of Milton H. Erickson. Phoenix: Zeig, Tucker \& Theisen, Inc.

Recebido em 27.09.2010

Primeira decisão editorial em 29.04.2013

Versão final em 07.05.2013

Aceito em 14.05.2013 